\title{
Two Enteropathogenic Escherichia coli Strains Representing Novel Serotypes and Investigation of Their Roles in Adhesion
}

\author{
Jing Wang ${ }^{1,2}$, HongBo Jiao ${ }^{4}$, XinFeng Zhang ${ }^{5}$, YuanQing Zhang ${ }^{6}$, Na Sun ${ }^{3}$, Ying Yang ${ }^{3}$, Yi Wei $^{1,2}$, \\ Bin $\mathrm{Hu}^{3 *}$, and Xi Guo ${ }^{1,2 *}$ \\ 'TEDA Institute of Biological Sciences and Biotechnology, Nankai University, 23 Hongda Street, TEDA, Tianjin \\ 300457, P.R. China \\ ${ }^{2}$ The Key Laboratory of Molecular Microbiology and Technology, Ministry of Education, 23 Hongda Street, TEDA, \\ Tianjin 300457, P.R. China \\ ${ }^{3}$ Shandong Center for Disease Control and Prevention, 16992 City Ten Road, Jinan 250014, Shandong, P.R. China \\ ${ }^{4}$ LanLing Center for Disease Control and Prevention, 1 City Huibao Road, Lanling 276000, Lanling Shandong, P.R. China \\ ${ }^{5}$ Taian Center for Disease Control and Prevention, 33 Changcheng Road, Taian 271000, Shandong, P.R. China \\ ${ }^{6}$ Jinan KeJia Medical Laboratory, Inc., 800 Minghu West Road, Jinan 250001, Shandong, P.R. China
}

Enteropathogenic Escherichia coli (EPEC), which belongs to the attaching and effacing diarrheagenic E. coli strains, is a major causative agent of life-threatening diarrhea in infants in developing countries. Most EPEC isolates correspond to certain $O$ serotypes; however, many strains are nontypeable. Two EPEC strains, EPEC001 and EPEC080, which could not be serotyped during routine detection, were isolated. In this study, we conducted an in-depth characterization of their putative 0 -antigen gene clusters (O-AGCs) and also performed constructed mutagenesis of the O-AGCs for functional analysis of $\mathrm{O}$-antigen $(\mathrm{OAg})$ synthesis. Sequence analysis revealed that the occurrence of 0 -AGCs in EPECO01 and E. coli 0132 may be mediated by recombination between them, and EPEC080 and E. coli 02/050 might acquire each O-AGC from uncommon ancestors. We also indicated that OAgknockout bacteria were highly adhesive in vitro, except for the EPEC001 wzy derivative, whose adherent capability was less than that of its wild-type strain, providing direct evidence that $\mathrm{OAg}$ plays a key role in EPEC pathogenesis. Together, we identified two EPEC $O$ serotypes in silico and experimentally, and we also studied the adherent capabilities of their OAgs, which highlighted the fundamental and pathogenic role of OAg in EPEC.

Keywords: Enteropathogenic Escherichia coli, O-antigen, O-antigen gene cluster, serotype, adhesion

Received: May 13, 2021 Accepted: July 14, 2021

First published online: July 15, 2021

*Corresponding authors B. $\mathrm{Hu}$

Phone: +86-0531-82679738 Fax: $+86-531-82679750$

E-mail:wubz9670@126.com X. Guo

Phone: $+86-22-66229574$

Fax: +86-22-66229584

E-mail: guoxi@nankai.edu.cn

pISSN 1017-7825

elSSN 1738-8872

Copyright(C) 2021 by

The Korean Society for

Microbiology and

Biotechnology

\section{Introduction}

Escherichia coli, the predominant facultative anaerobe in human colonic flora, comprises both commensal and pathogenic strains, with the latter causing various diseases from gastroenteritis to extraintestinal infections [1]. To date, eight pathovars of $E$. coli have been reported, which can be broadly classified as diarrhoeagenic and extraintestinal E. coli (ExPEC) [2,3]. Among the diarrheagenic E. coli, enteropathogenic E. coli (EPEC) is a major causative agent of life-threatening diarrhea in infants in developing countries [4].

Lipopolysaccharide (LPS), a component of the outer membrane, is located exclusively in the outermost layer of gram-negative bacteria. LPS typically consists of three components: lipid A, core oligosaccharides and O-antigen $(\mathrm{OAg})$. The OAg is the most surface-exposed part of the LPS, and is usually a polymer comprising repeating oligosaccharide units (O-units), each containing two to eight sugar residues from a broad range of common or rare sugars and their derivatives [5].

The variability in OAgs is the basis for the serotyping systems of gram-negative bacteria. The antigenic scheme of E. coli was first presented by Fritz Kauffmann in the 1940s, and to date, more than 180 serotypes have been internationally recognized [6]. The genes for OAg synthesis are usually present at a specific locus on the chromosome, named the $\mathrm{O}$-antigen gene cluster (O-AGC). These genes are normally classified into three groups: nucleotide sugar precursor synthesis genes (for biosynthesis of nucleotide sugar precursors specific to OAg), glycosyltransferase genes (for the sequential and specific addition of sugars that generate the O-units), and OAg processing genes (for OAg assembly) [7]. In E. coli strains, O-AGC usually maps between the housekeeping genes, galF and gnd, with a few exceptions, including O8/O9/O9a located between gnd and hisI genes $[8,9]$ and O62, which is located far from the galF and gnd loci [10]. 
Currently, two pathways have been identified as responsible for the assembly of E. coli OAgs: the Wzx/Wzydependent pathway and the $\mathrm{ABC}$ transporter (Wzm/Wzt)-dependent pathway. In each pathway, OAg synthesis is initiated by the transfer of sugar phosphate from NDP-sugar to undecaprenyl phosphate (Und-P) [11]. In the $\mathrm{Wzx} / \mathrm{Wzy}$ pathway, other sugars are transferred sequentially to Und-PP-sugar to form O-units, which are then flipped by Wzx and polymerized by Wzy to generate the polymer [12]. In the Wzm/Wzt pathway, the sugars for each O-unit are sequentially added to Und-PP-sugar, designated as the "primer," and the process does not stop until the complete repeating-unit polymer is generated, followed by the translocation of UndPP-OAg from the cytoplasm to periplasm by the ABC transporter [13].

During the pathogenesis, adhesion to epithelial cells is a key virulence function. EPEC adheres to the enterocytes in the small bowel and enables the colonization of intestinal epithelium, forming attaching and effacing (A/E) lesions and translocating effector proteins into host cell cytoplasm [14]. The majority of the genes required for $\mathrm{A} / \mathrm{E}$ lesion formation are grouped within a pathogenicity island named the 'locus of enterocyte effacement' (LEE) [15]. Two LEE-encoded adhesins, type III secretion system (TTSS) EspA filaments and the outer-membrane adhesin, intimin (interacted with its translocated receptor Tir), have been reported possessing the ability to facilitate the adhesion of EPEC to intestinal epithelium [16]. In addition, the non-LEE-encoded factors, including the type IV bundle-forming pilus (BFP) and EspFu can also trigger EHPC adhesion [16, 17]. Several studies on other bacteria by comparing the wild-type strain with the OAg-deficient mutant provided evidence that OAg plays a key role in bacterial adhesion, thus affecting pathogenesis [18-20], as well as enabling the bacteria to evade the host immune system $[21,22]$. However, the adherent and pathogenic role of OAg in EPEC is still largely unknown. The aim of this study was to characterize the putative novel O-AGC loci of two EPEC strains isolated from Shandong Province, China, during routine detection. Moreover, mutagenesis of the OAGCs was constructed and used for functional analysis of the loci, and the roles of the OAgs of these two strains in virulence were also investigated via in vitro experiments.

\section{Materials and Methods}

\section{Bacterial Strains, Plasmids, and Growth Conditions}

The two EPEC strains, EPEC001 from a patient's fecal sample, and EPEC080 from a goat were isolated by the Shandong Center for Disease Control and Prevention. Details of EPEC001, EPEC080, their derivatives, and plasmids are described in Table 1. The primers used for mutant construction are also listed in Table 1. All strains were routinely cultured in $2 \times$ YT medium ( $16 \mathrm{~g}$ tryptone, $10 \mathrm{~g}$ yeast extract, and $5 \mathrm{~g}$ sodium chloride per liter). When necessary, the media were supplemented with chloramphenicol $(\mathrm{Cm}, 25 \mu \mathrm{g} / \mathrm{ml})$ or blasticidin $(\mathrm{Bs}, 200 \mu \mathrm{g} / \mathrm{ml})$.

\section{Genome Sequencing, Assembly, and Annotation}

Genomic DNA was extracted from $1.5 \mathrm{ml}$ of overnight bacterial culture (approximately $10^{8}$ colony-forming units $(\mathrm{CFU}) / \mathrm{ml}$ ) using a DNA extraction kit (Tiangen, China) according to manufacturer's instructions. Subsequently, the DNA was sheared, polished, and prepared using the Illumina Sample Preparation Kit. Genome sequencing was performed using the Solexa sequencing technology (Illumina Inc., USA) and the reads obtained were assembled using the de novo genome-assembly program Velvet to generate a multi-contig draft genome. Artemis [23] was used to annotate genes, and the lockMaker program [24] was used to identify conserved motifs. BLAST and PSI-BLAST [25] were used to search genes and proteins against the available databases including GenBank (www.ncbi.nlm.nih.gov/genbank) and Pfam protein families database (pfam.sanger.ac.uk). TMHMM v2.0 (http://www.cbs.dtu.dk/services/TMHMM-2.0/) was used to identify potential transmembrane domains within protein sequences. The putative O-AGC between the galF and gnd genes of each strain was retrieved from the genomes for further analysis.

\section{Construction of Mutants}

The mutant strains were constructed using a $\lambda$ Red recombinase system as previously described[26]. Briefly, first, the plasmid pSim17 was electroporated into the wild-type (WT) strain to enable a direct homologous recombination with PCR products. Following this, the chloramphenicol acetyltransferase (cat) gene from plasmid pKD3 was amplified using 50 nucleotides homologous to the flanking regions of the DNA target segment and the PCR product was transformed into the pSim 17-containing wild-type strain that could express recombinase. The mutants with the introduced cat gene were confirmed by PCR and sequencing.

\section{LPS Preparation and Analysis}

LPS was extracted using the hot aqueous-phenol method as previously described [27]. The extracted LPSs were separated by using $12 \%$ SDS-PAGE at $50 \mathrm{~V}$ for $30 \mathrm{~min}$ and $100 \mathrm{~V}$ for $2 \mathrm{~h}$ and subsequently, they were visualized by silver staining using the Fast Silver Stain Kit (No. P0017S, Beyotime, China) according to manufacturer's protocol. The gel image was captured using a GS900 Calibrated Densitometer (BioRad Laboratories, USA) under "silver stain" mode.

\section{Cell Culture and Bacterial Adhesion}

HeLa cells were cultured in high-glucose Dulbecco's modified Eagle's medium containing $10 \%$ fetal bovine serum and penicillin-streptomycin-glutamine and they were grown at $37^{\circ} \mathrm{C}$ under $5 \% \mathrm{CO}_{2}$. For adhesion assays, cells grown overnight to approximately $80 \%$ confluence were seeded into 12 -well tissue culture plates at a concentration of $1 \times 10^{6}$ cells per well and they were maintained as differentiated monolayers. Next, bacteria in the logarithmic growth phase were added to the cell monolayers at an MOI of of 10 . After $6 \mathrm{~h}$ of incubation at $37^{\circ} \mathrm{C}$, the 
Table 1. Strains, plasmids, and primers.

\begin{tabular}{|c|c|}
\hline Strain/plasmid/primer & Description \\
\hline \multicolumn{2}{|l|}{ Bacterial strain } \\
\hline EPEC001 & Wild-type strain \\
\hline EPEC001 $\triangle \mathrm{OAg}$ & Deletion of the entire O-antigen gene cluster, $\mathrm{Cm}^{\mathrm{r}}$ \\
\hline $\mathrm{EPEC} 001 \Delta w z y$ & Deletion of the $w z y$ gene, $\mathrm{Cm}^{\mathrm{r}}$ \\
\hline EPEC080 & Wild-type strain \\
\hline EPEC080 $\Delta \mathrm{OAg}$ & Deletion of $\mathrm{O}$-antigen gene cluster, $\mathrm{Cm}^{\mathrm{r}}$ \\
\hline $\mathrm{EPEC} 080 \Delta w z y$ & Deletion of the $w z y$ gene, $\mathrm{Cm}^{\mathrm{r}}$ \\
\hline \multicolumn{2}{|l|}{ Plasmid } \\
\hline pSim17 & Plasmid carrying genes encoding lambda Red recombinase system, $\mathrm{Bs}^{\mathrm{r}}$ \\
\hline pKD3 & Template for PCR amplification of lambda Red recombinase-mediated recombination, $\mathrm{Cm}^{\mathrm{r}}$ \\
\hline Primer & Nucleotide sequences $\left(5^{\prime}-3^{\prime}\right)^{a}$ \\
\hline FOAg001 & $\begin{array}{l}\text { ACATTTATTGAAACCAATATTGTTGGTACTTATGTCCTTTTGGAAGCCGCCATATGAA } \\
\text { TATCCTCCTTAG, forward primer for EPEC001 O-antigen gene cluster deletion }\end{array}$ \\
\hline ROAg001 & $\begin{array}{l}\text { TATAAGCATCAAAACATATCCTAGCGGCTTTTACATTTCCAGTTAACATTGTGTAGGC } \\
\text { TGGAGCTGCTTCG, reverse primer for EPEC001 O-antigen gene cluster deletion }\end{array}$ \\
\hline Fwzy001 & $\begin{array}{l}\text { TTATTAAATATATGTTTATCAAGGCTTTCTACAAATCCTTTGATTTTATTCATATGAAT } \\
\text { ATCCTCCTTAG, forward primer for EPEC001 wzy gene deletion }\end{array}$ \\
\hline Rwzy001 & $\begin{array}{l}\text { ATCATTCCATAATATTAACCATATTAATGATACTACATAAGTATTAAAAGGTGTAGGCT } \\
\text { GGAGCTGCTTCG, reverse primer for EPEC001 } w z y \text { gene deletion }\end{array}$ \\
\hline FOAg080 & $\begin{array}{l}\text { CTGGCTGCTGAAAGCCATGTGGATCGTTCCATTACAGGCCCTGCGGCATTCATATGA } \\
\text { ATATCCTCCTTAG, forward primer for EPEC080 O-antigen gene cluster deletion }\end{array}$ \\
\hline ROAg080 & $\begin{array}{l}\text { CTACCAGCAGCCACGGGATCATGCCGCTGTCGCAGTAAGCGAAATCACGGGTGTAG } \\
\text { GCTGGAGCTGCTTCG, reverse primer for EPEC } 080 \text { O-antigen gene cluster deletion }\end{array}$ \\
\hline Fwzy080 & $\begin{array}{l}\text { TTGGCTTTTGCGTTTATTTCTATTTATTACAAGGCTAAGGCAATAAGGCTCATATGAA } \\
\text { TATCCTCCTTAG, forward primer for EPEC080 wzy gene deletion }\end{array}$ \\
\hline Rwzy080 & $\begin{array}{l}\text { TAATTCACTCATGCGCAAAGAAAATGCTGGCACAAACGAAAATAAAACTAGTGTAGG } \\
\text { CTGGAGCTGCTTCG, reverse primer for EPEC080 } w z y \text { gene deletion }\end{array}$ \\
\hline Vcat & $\begin{array}{l}\text { ATGGACAACTTCTTCGCC, forward primer for each mutant verification, designed in cat gene of } \\
\text { pKD3 }\end{array}$ \\
\hline VOAg001 & $\begin{array}{l}\text { ACGAGGCGTTTCAAGAGA, reverse primer for EPEC001 } \triangle \text { OAg verification, designed in } g n d \text { of } \\
\text { EPEC001, 856bp }\end{array}$ \\
\hline Vwzy001 & $\begin{array}{l}\text { GTTGGAAATAAATGGCTGTG, reverse primer for EPEC001 } 1 w z y \text { verification, designed in orf } 11 \\
\text { of EPEC001 O-AGC, 774bp }\end{array}$ \\
\hline VOAg080 & $\begin{array}{l}\text { ACTAACCACTGGACTTGCTC, reverse primer for EPEC } 080 \Delta \mathrm{OAg} \text { verification, designed in } g n d \\
\text { of EPEC080, } 1002 \mathrm{bp}\end{array}$ \\
\hline Vwzy080 & $\begin{array}{l}\text { CCACTGTTGGCTTTTGTTT, reverse primer for EPEC } 080 \Delta w z y \text { verification, designed in orf } 12 \text { of } \\
\text { EPEC } 080 \text { O-AGC, } 867 \mathrm{bp}\end{array}$ \\
\hline
\end{tabular}

${ }^{a}$ Boldface characters indicate the 50 nucleotides homologous to the initial and final portions of the target DNA segment.

cells were washed extensively with phosphate-buffered saline (PBS) three times to remove non-adherent bacteria and they were permeabilized with $0.2 \%$ Triton X-100. The adhesive bacteria were collected, serially diluted in PBS, and spread onto Luria-Bertani agar for counting bacterial CFUs. Three independent experiments were performed for each strain. Statistical significance was determined using an unpaired Student's $t$-test. A $p$-value of $<0.05$ was considered statistically significant.

\section{Nucleotide Sequence Accession Number}

The DNA sequences of the O-AGCs from EPEC001 and EPEC080 were deposited in GenBank database under accession numbers MW690110 and MW690111, respectively.

\section{Results}

\section{Functional Annotation of Putative O-AGCs}

The putative O-AGC of EPEC001 is 12,344 bp in length, and it contains 12 open reading frames (orfs) with the same transcriptional direction from galF to gnd (Fig. 1, Table 2). orf1 to 4 are identical to the dTDP-glucose 4,6dehydratase $(\mathrm{rmlB})$, dTDP-4-dehydrorhamnose reductase $(\mathrm{rmlD})$, glucose-1-phosphate thymidylyltransferase $(\mathrm{rmlA})$, and dTDP-4-dehydrorhamnose 3,5-epimerase $(\mathrm{rmlC})$ genes, respectively. A set of genes in the order rmlBDAC is usually localized at the 5' end of O-AGC and the products are responsible for the biosynthesis of dTDP-L-Rha, the nucleotide precursor of L-Rha, which is usually found as a component of OAg. orf6 was assigned as $g l f$, which encodes a UDP-galactopyranose mutase catalyzing the formation of UDP-D-Galf, which is the nucleotide precursor of D-Galf, from UDP-D-Gal. orf5 and orf10 were presumptively identified as $w z x$ and $w z y$, respectively, using BLAST. Additionally, Orf5 contains 11 predicted transmembrane (TM) domains, which is the typical number for OAg flippase (Wzx), and Orf10 contains nine predicted TM domains, which is typical for OAg polymerase (Wzy). orf9, orf11, and orf12 were all assigned as glycosyltransferase genes. Moreover, orf9 was predicted as the rhamnosyltransferase gene and orf 12 as the galactofuranosyltransferase gene, which suggests that the occurrence of L-Rha and Galfresidues in EPEC001 OAg is very likely and is in accordance with the existence of 


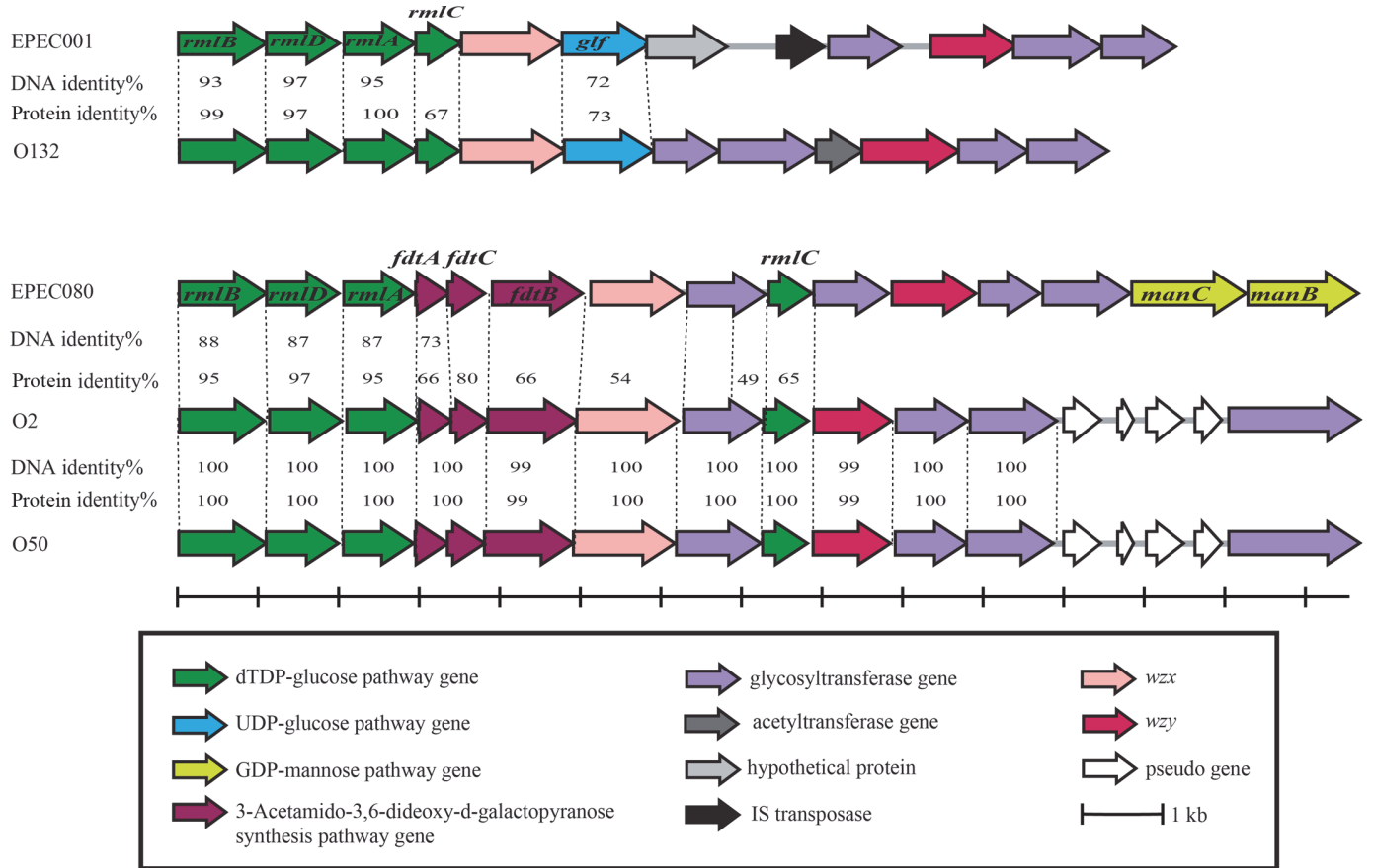

Fig. 1. O-antigen gene clusters of EPEC001 and EPEC080, and comparisons with each related serotype(s). $r m l A$, glucose-1-phosphate thymidylyltransferase gene; $r m l B$, dTDP-D-glucose 4,6-dehydratase gene; $r m l C$, dTDP-4-keto-6deoxy-D-glucose 3,5-epimerase gene; $r m l D$, dTDP-6-deoxy-L-mannose-dehydrogenase gene; glf, UDP-galactopyranose mutase gene; $f d t A$, dTDP-6-deoxy-hex-4-ulose isomerase gene; $f d t B$, dTDP-6-deoxy-D-xylo-hex-3-ulose aminase gene; $f d t C$, dTDP-D-Fuc3N acetylase gene; $\operatorname{man} B$, phosphomannomutase gene; $\operatorname{man} C$, mannose-1-phosphate guanylyltransferase gene; $w z x, \mathrm{O}$-antigen flippase gene; $w z y, \mathrm{O}$-antigen polymerase gene.

rmlBDAC (orf1 to 4) and $g l f$ (orf6) genes. Among the remaining two orfs, the product of orf 8 was predicted to be the ISAs1 family transposase and the product of orf7 exhibited no similarity to any functionally characterized/ identified protein, and therefore, it was assigned as a hypothetical protein.

The putative O-AGC of EPEC080 also maps between galF and gnd genes, with 14,550 bp in length and 15 orfs being annotated (Fig. 1, Table 2). orf1 to 3 and orf9 were annotated as $r m l B, r m l D$, $r m l A$, and $r m l C$, respectively. orf4 to 6 , the three orfs downstream of $r m l A$, were assigned to the isomerase $(f d t A), \mathrm{N}$-acetyltransferase $(f d t C)$, and transaminase $(f d t B)$ genes, respectively. The products of these three genes along with RmlA and RmlB are responsible for the synthesis of dTDP-D-Fuc3NAc from Glc-1-P. dTDP-D-Fuc3NAc is the nucleotide precursor of D-Fuc3NAc, which is a rare sugar occasionally occurring in OAg. orf14 and orf15 were assigned as the mannose-1-phosphate guanylyltransferase $(\operatorname{man} C)$ and phosphomannomutase $(\operatorname{man} B)$ genes, respectively. ManB, ManC, and the phosphomannose isomerase, ManA, are involved in the synthesis of GDP-D-Man, the nucleotide precursor of D-Man, from Fru-6-P. However, the manA gene is not always located in O-AGC. orf7 and orf 11 were functionally annotated as $w z x$ and $w z y$, respectively. TM domain analysis revealed that Orf7 contained 10 TM segments and Orf11 contained eight TM segments, each exhibiting typical features of O-antigen flippase (Wzx) and O-antigen polymerase (Wzy). The remaining four orfs were predicted to encode glycosyltransferases. Furthermore, among them, orf10,11, and 13 were assigned to the rhamnosyltransferase, glucosyltransferase, and mannosyltransferase genes, respectively. This indicates the existence of L-Rha, D-Glc, and D-Man residues in EPEC080 OAg, and it partly verifies the gene annotation of O-AGC.

\section{Construction of Mutant Strains}

To determine the functional roles of putative O-AGCs, mutant strains with O-AGC and $w z y$ deletions were constructed for EPEC001 and EPEC080, respectively, and verified by PCR amplification and subsequent sequencing. For PCR, the common forward primer was designed in the cat gene of pKD3 that substitutes the DNA segment of the deleted gene(s) and the reverse primer was designed in the orf downstream of the targeted gene(s) (Table 1). As shown in the agarose gel electrophoresis of all PCR products (Fig. 2), each mutant strain generated a specific and length-correct band, with the corresponding wild-type strain (control) giving no PCR product. All constructed mutant strains were further confirmed by sequencing.

Functional Confirmation of O-AGCs

As shown in the LPS profile (Fig. 3), EPEC001 generated a WT bimodal distribution of LPS, characterized by a first band of lipid A-core and additional bands corresponding to O-units. However, the mutant EPEC001 $\triangle \mathrm{OAg}$ 
Table 2. Characteristics of open reading frames (ORFs) in the $\mathrm{O}$-antigen gene clusters of EPEC001 and EPEC080.

\begin{tabular}{|c|c|c|c|c|c|c|}
\hline $\begin{array}{l}\text { Orf } \\
\text { no. }\end{array}$ & $\begin{array}{l}\text { Gene } \\
\text { name }\end{array}$ & $\begin{array}{l}\text { Position of the } \\
\text { gene }\end{array}$ & $\begin{array}{c}\mathrm{G}+\mathrm{C} \\
\text { content } \\
(\%)\end{array}$ & $\begin{array}{l}\text { Similar protein(s), strain(s) } \\
\text { (GenBank accession no.) }\end{array}$ & $\begin{array}{l}\text { \%Identical/ } \\
\text { \%Similar } \\
\text { (total no. of aa) }\end{array}$ & $\begin{array}{l}\text { Putative function of } \\
\text { protein }\end{array}$ \\
\hline \multicolumn{7}{|c|}{$\overline{\text { EPEC001 }}$} \\
\hline 1 & $r m l B$ & $1 . .1086$ & 42.44 & $\begin{array}{l}\text { dTDP-glucose 4,6-dehydratase [Escherichia } \\
\text { coli] (WP_052925278.1) }\end{array}$ & $100 / 100(361)$ & dTDP-glucose 4,6-dehydratase \\
\hline 2 & $r m l D$ & $1086 . .1985$ & 47.55 & $\begin{array}{l}\text { dTDP-4-dehydrorhamnose reductase } \\
\text { [Escherichia coli] (WP_046201417.1) }\end{array}$ & $99 / 100(299)$ & $\begin{array}{l}\text { dTDP-4-dehydrorhamnose } \\
\text { reductase }\end{array}$ \\
\hline 3 & $r m l A$ & $2043 . .2918$ & 43.26 & $\begin{array}{l}\text { glucose-1-phosphate thymidylyltransferase } \\
\text { RfbA [Escherichia coli] (WP_046201417.1) }\end{array}$ & $99 / 100(291)$ & $\begin{array}{l}\text { Glucose-1-phosphate } \\
\text { thymidylyltransferase }\end{array}$ \\
\hline 4 & $r m l C$ & $2927 . .3481$ & 32.43 & $\begin{array}{l}\text { dTDP-4-dehydrorhamnose 3,5-epimerase } \\
\text { [Escherichia coli] (WP_057080958.1) }\end{array}$ & $99 / 100(184)$ & $\begin{array}{l}\text { dTDP-4-dehydrorhamnose } \\
\text { 3,5-epimerase }\end{array}$ \\
\hline 5 & $w z x$ & $3490 . .4728$ & 34.22 & $\begin{array}{l}\text { O34 family O-antigen flippase [Escherichia } \\
\text { coli] (WP_097479960.1) }\end{array}$ & $51 / 71(412)$ & flippase \\
\hline 6 & glf & $4731 . .5822$ & 32.6 & $\begin{array}{l}\text { UDP-galactopyranose mutase [Escherichia } \\
\text { coli] (WP_033560995.1) }\end{array}$ & $75 / 85(363)$ & UDP-galactopyranose mutase \\
\hline 7 & & $5825 . .6814$ & 32.12 & $\begin{array}{l}\text { hypothetical protein [Escherichia coli] } \\
\text { (WP_053273170.1) }\end{array}$ & $99 / 99(329)$ & hypothetical protein \\
\hline 8 & & $7459 . .8013$ & 40.24 & $\begin{array}{l}\text { ISAs1 family transposase [Escherichia coli] } \\
\text { (MBJ0238419.1) }\end{array}$ & 96/97 (184) & $\mathrm{H}$ repeat-associated protein \\
\hline 9 & & $8068 . .8961$ & 32.66 & $\begin{array}{l}\text { glycosyltransferase [Escherichia coli] } \\
\text { (WP_085446706.1) }\end{array}$ & $38 / 59(297)$ & $\begin{array}{l}\text { glycosyltransferase family } 2 \\
\text { protein }\end{array}$ \\
\hline 10 & $w z y$ & $9274 . .10335$ & 29.75 & $\begin{array}{l}\text { EpsG family protein [Cronobacter } \\
\text { muytjensii] (WP_075192411.1) }\end{array}$ & $47 / 69(353)$ & polymerase \\
\hline 11 & & $10345 . .11439$ & 29.22 & $\begin{array}{l}\text { glycosyltransferase family } 4 \text { protein } \\
\text { [Cronobacter muytjensii] } \\
\text { (WP_083605367.1) }\end{array}$ & $46 / 64(364)$ & glycosyltransferase \\
\hline 12 & & $11436 . .12344$ & 31.35 & $\begin{array}{l}\text { glycosyltransferase family } 2 \text { protein } \\
\text { [Enterobacter asburiae] (WP_150182824.1) }\end{array}$ & $62 / 77(303)$ & $\begin{array}{l}\text { Galactofuranosyltransferase } \\
\text { GlfT1 }\end{array}$ \\
\hline \multicolumn{7}{|c|}{ EPEC080 } \\
\hline 1 & $r m l B$ & $1 . .1086$ & 43.18 & $\begin{array}{l}\text { dTDP-glucose 4,6-dehydratase [Escherichia } \\
\text { coli] (WP_029399178.1) }\end{array}$ & $100 / 100(361)$ & dTDP-glucose 4,6-dehydratase \\
\hline 2 & $r m l D$ & $1086 . .1985$ & 46.11 & $\begin{array}{l}\text { dTDP-4-dehydrorhamnose reductase } \\
\text { [Escherichia coli] (WP_029399176.1) }\end{array}$ & $100 / 100(299)$ & $\begin{array}{l}\text { dTDP-4-dehydrorhamnose } \\
\text { reductase }\end{array}$ \\
\hline 3 & $r m l A$ & $2043 . .2921$ & 43.34 & $\begin{array}{l}\text { glucose-1-phosphate thymidylyltransferase } \\
\text { RfbA [Escherichia coli] (WP_029399175.1) }\end{array}$ & $100 / 100(292)$ & $\begin{array}{l}\text { Glucose-1-phosphate } \\
\text { thymidylyltransferase } 1\end{array}$ \\
\hline 4 & $f d t A$ & $2935 . .3354$ & 32.85 & $\begin{array}{l}\text { FdtA/QdtA family cupin domain- } \\
\text { containing protein [Cedecea lapagei] } \\
(\mathrm{WP} 126355658.1)\end{array}$ & $66 / 83(139)$ & $\begin{array}{l}\text { TDP-4-oxo-6-deoxy-alpha-D- } \\
\text { glucose-3,4-oxoisomerase }\end{array}$ \\
\hline 5 & $f d t C$ & $3332 . .3796$ & 36.77 & $\begin{array}{l}\text { N-acetyltransferase [Escherichia coli] } \\
\text { (EFN7827253.1) }\end{array}$ & $100 / 100(154)$ & $\begin{array}{l}\text { dTDP-3-amino-3,6-dideoxy- } \\
\text { alpha-D-galactopyranose 3-N- } \\
\text { acetyltransferase }\end{array}$ \\
\hline 6 & $f d t B$ & 3801..4922 & 33.77 & $\begin{array}{l}\text { DegT/DnrJ/EryC1/StrS family } \\
\text { aminotransferase }[\text { Escherichia coli] } \\
(\mathrm{HAO} 2821289.1)\end{array}$ & $99 / 99(373)$ & $\begin{array}{l}\text { dTDP-3-amino-3,6-dideoxy- } \\
\text { alpha-D-galactopyranose } \\
\text { transaminase }\end{array}$ \\
\hline 7 & $w z x$ & $4906 . .6177$ & 30.47 & $\begin{array}{l}\text { O50 family O-antigen flippase [Escherichia } \\
\text { coli] (EFN5080582.1) }\end{array}$ & $54 / 74(423)$ & flippase \\
\hline 8 & & $6190 . .7221$ & 31.2 & $\begin{array}{l}\text { glycosyltransferase family } 4 \text { protein } \\
\text { [Enterobacter cloacae complex sp.] } \\
\text { (WP_133294767.1) }\end{array}$ & $53 / 71(343)$ & $\begin{array}{l}\text { glycosyltransferase family } 4 \\
\text { protein }\end{array}$ \\
\hline 9 & $r m l C$ & $7234 . .7767$ & 34.08 & $\begin{array}{l}\text { dTDP-4-dehydrorhamnose 3,5-epimerase } \\
\text { [Escherichia coli] (EEW2230532.1) }\end{array}$ & $99 / 100(177)$ & $\begin{array}{l}\text { dTDP-4-dehydrorhamnose } \\
\text { 3,5-epimerase }\end{array}$ \\
\hline 10 & & $7793 . .8722$ & 30.96 & $\begin{array}{l}\text { glycosyltransferase family } 2 \text { protein } \\
\text { [Escherichia coli] (WP_063610376.1) }\end{array}$ & $48 / 69(309)$ & rhamnosyltransferase \\
\hline 11 & $w z y$ & $8762 . .9805$ & 27.2 & $\begin{array}{l}\text { EpsG family protein [Escherichia coli] } \\
\text { (WP_089723541.1) }\end{array}$ & $45 / 66(347)$ & polymerase \\
\hline 12 & & $9844 . .10599$ & 28.04 & $\begin{array}{l}\text { glycosyl transferase group } 2 \text { family protein } \\
\text { [Escherichia coli] (OAC41241.1) }\end{array}$ & $58 / 76(251)$ & $\begin{array}{l}\text { UDP-Glc:alpha-D-GlcNAc- } \\
\text { diphosphoundecaprenol beta- } \\
\text { 1,3-glucosyltransferase WfgD }\end{array}$ \\
\hline 13 & & $10613 . .11722$ & 30.21 & $\begin{array}{l}\text { glycosyltransferase [Croceivirga radicis] } \\
\text { (WP_080317782.1) }\end{array}$ & $52 / 71(369)$ & $\begin{array}{l}\text { Phosphatidyl-myo-inositol } \\
\text { mannosyltransferase }\end{array}$ \\
\hline 14 & $\operatorname{man} C$ & $11738 . .13159$ & 36.42 & $\begin{array}{l}\text { mannose-1-phosphate guanylyltransferase/ } \\
\text { mannose-6-phosphate isomerase } \\
\text { [Escherichia coli](WP_029399160.1) }\end{array}$ & $100 / 100(473)$ & $\begin{array}{l}\text { Mannose-1-phosphate } \\
\text { guanylyltransferase } 1\end{array}$ \\
\hline 15 & $\operatorname{man} B$ & $13180 . .14550$ & 54.48 & $\begin{array}{l}\text { phosphomannomutase/ } \\
\text { phosphoglucomutase [Escherichia coli] } \\
\text { (EFA9345916.1) }\end{array}$ & $99 / 99(456)$ & $\begin{array}{l}\text { Phosphomannomutase/ } \\
\text { phosphoglucomutase }\end{array}$ \\
\hline
\end{tabular}




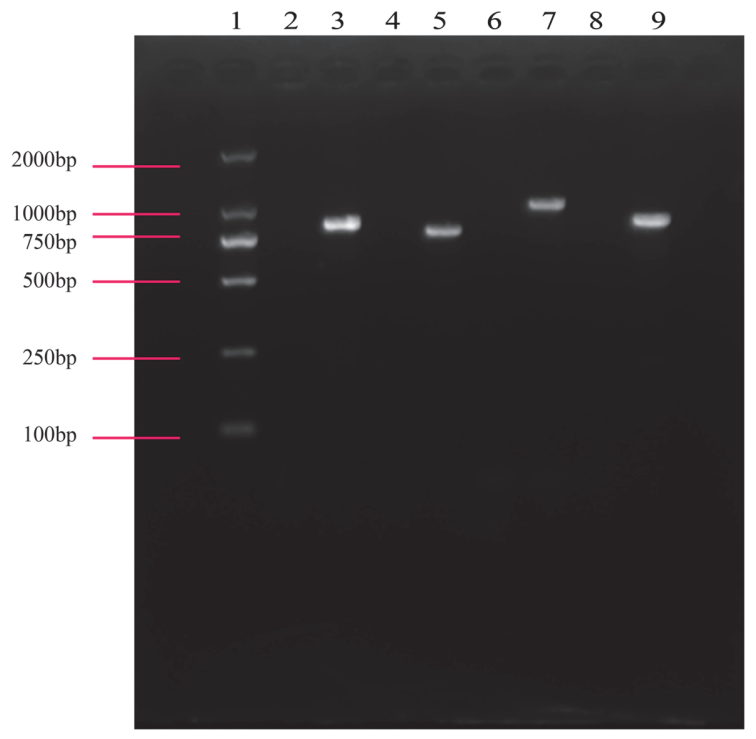

Fig. 2. Agarose gel electrophoresis of all PCR products from the mutant strains and their wild-type controls. Lane 1: DL2000 DNA marker; lane 2: EPEC001 (Vcat/VOAg001); lane 3: EPEC001 $\triangle O A g$ (Vcat/VOAg001); lane 4: EPEC001 (Vcat/Vwzy001); lane 5: EPEC001 $w z y$ (Vcat/Vwzy001); lane 6: EPEC080 (Vcat/VOAg080); lane 7: EPEC080 0 OAg (Vcat/ VOAg080); lane 8: EPEC080 (Vcat/Vwzy080); lane 9: EPEC080 $w z y$ (Vcat/Vwzy080).

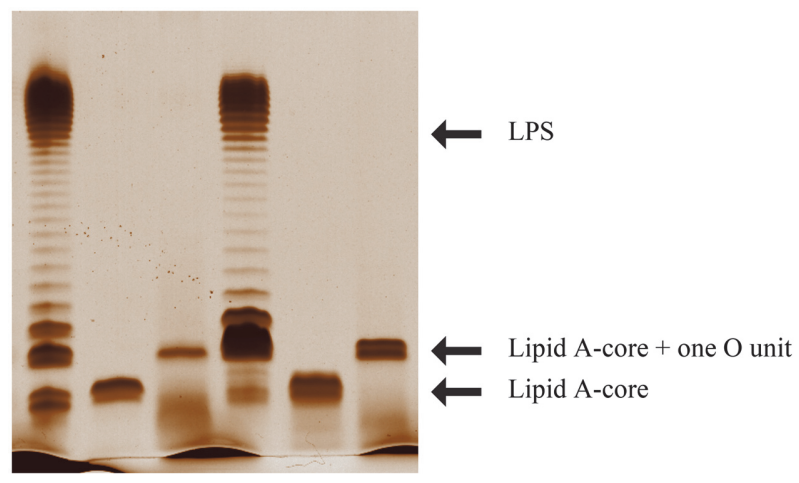

Fig. 3. Lipopolysaccharide profiles of strains EPEC001, EPEC080, and their derivatives. The extracts were electrophoresed on 12\% SDS-PAGE and stained by silver staining. From left to right: EPEC001 expressing complete LPS, EPEC001 $\triangle \mathrm{OAg}$ expressing rough LPS, EPEC001 $\Delta w z y$ expressing semi-rough LPS, EPEC080 expressing complete LPS, EPEC080 $\triangle \mathrm{OAg}$ expressing rough LPS, and EPEC080 $\Delta$ wzy expressing semi-rough LPS.

only generated one band of lipid A-core and no attached OAg, and the mutant EPEC001 $1 w z y$ showed a semirough LPS phenotype with only one O-unit substitution on the lipid A-core. These results collectively indicate that the locus between $g a l F$ and $g n d$ is effectively involved in the biosynthesis of EPEC001 OAg and that orf 10 encodes the O-antigen polymerase (Wzy) responsible for the OAg assembly in EPEC001. Similar to EPEC001 and its derivatives, EPEC080 exhibited a complete LPS profile, while the EPEC080 $\triangle \mathrm{OAg}$ strain showed a rough LPS phenotype and the EPEC080 $\Delta w z y$ strain showed a semi-rough LPS phenotype. Thus, we demonstrated that the $\mathrm{O}$-AGC of EPEC080 maps between galF and gnd, and the wzy (orf11) gene of the strain is involved in OAg assembly.

\section{The Role of OAgs in Adhesion}

Except for the enteroinvasive E. coli, adhesion to host cells is a requirement for all E.coli pathovars and it is a key stage in bacterial infection. To investigate the pathogenic role of OAg, we assessed its adhesion ability to the HeLa cells of EPEC001, EPEC080, and their OAg derivatives (Fig. 4). After $6 \mathrm{~h}$ of infection, compared to the EPEC080 WT strain, the mutant complete loss of O-AGC and the mutant loss of $w z y$ both exhibited increased bacterial adhesion (6-fold, $p=0.0067$ and 5.9-fold, $p=0.0061$, respectively). For EPEC001, the adhesion ability of its OAGC mutant also significantly increased as compared to that of the WT strain (5.9-fold, $p=0.0093$ ). However, the wzy mutant generated a completely opposite result, and the loss of wzy significantly decreased the bacterial adhesion level ( 0.16 -fold, $p=0.014)$. 


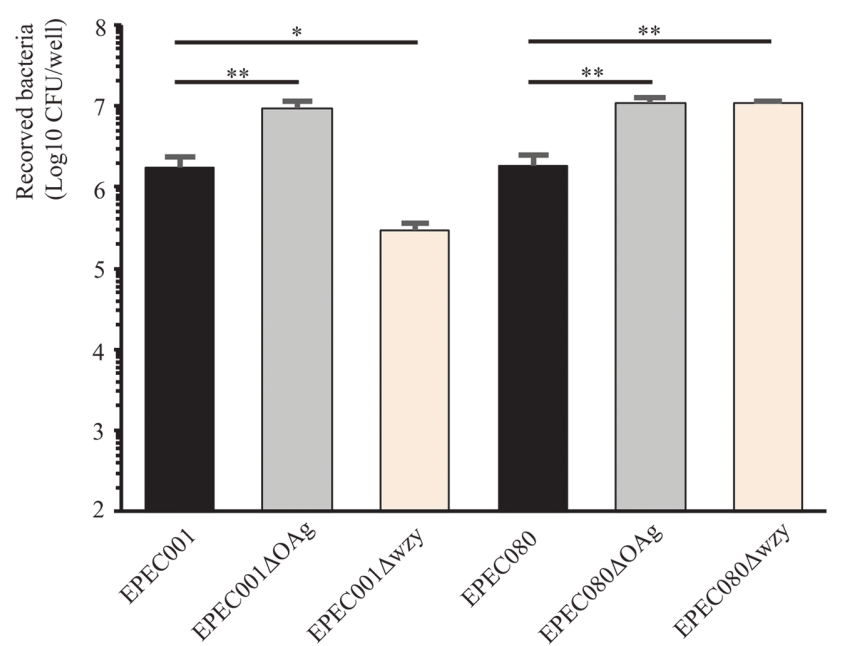

Fig. 4. Adherent capabilities of EPEC001, EPEC080, and their derivatives. Data are presented as means \pm standard deviations (SD) for three biological replicates. Statistical analysis was performed using the unpaired Student $t$-test. ${ }^{*} p<0.05$, ${ }^{* *} p<0.01$.

\section{Discussion}

In this study, we genetically characterized novel putative O-AGCs from two E. coli strains that could not be tested using Iguchi's O-genotyping PCR assay, which targets almost all known E. coli serotypes [28]. To date, more than $180 \mathrm{O}$ serotypes of $E$. coli strains have been identified based on their OAg variability. Several E. coli O serotypes are closely associated with human diseases with high morbidity and mortality rates. For example, the Shiga toxin-producing E. coli (STEC) O157:H7 is a well-known pathogenic clone that causes hemolytic-uremic syndrome and foodborne illnesses [29]. The "big six" non-O157 STEC strains (O26, O45, O103, O111, O121, and O145) cause less severe infections than O157. However, the severity of infection differs with different serotypes. Another example is the STEC O104:H4, which caused a widespread and severe foodborne illness epidemic in Germany in 2011 [30]. In recent years, strains representing novel serotypes and being associated with or as one of the dominant clones causing human diseases have been isolated and characterized [31-33]. Pair-to-pair alignment shows that the O-AGC of EPEC001 is close to that of E. coli O132 and the O-AGC of EPEC080 is related to that of E. coli O2/O50 (Fig. 1). Generally, products encoded by the six upstream genes including $w z x$ of EPEC001 O-AGC, share high percentages of protein identity levels (50 to 100) to the corresponding region of E. coli $\mathrm{O} 132 \mathrm{O}-\mathrm{AGC}$ with the right region being unique, which is probably the serotype determinant. Indeed, all glycosyltransferase genes and $w z y$, the possessing gene, which are considered highly sero-specific, were located at the 3 ' end of O-AGC. It seems that a recombination event occurred between the O-AGCs of EPEC001 and E. coli $\mathrm{O} 132$ and we propose that one of the recombination sites is located in the $r m l \mathrm{~A}$ gene since the DNA identity level of $r m l A$ was much higher than that of its downstream genes. Likewise, the first nine genes in the O-AGCs of EPEC080 and E. coli O2/O50 have the same order and they share 49 to $95 \%$ protein identity level. However, the DNA identity level of each gene pair is less than $90 \%$. Thus, it is proposed that both EPEC080 and E. coli O2/O50 have each acquired their respective O-AGC from uncommon ancestors instead of via recombination between them. As the diversity of serotypes is based on the structural variations of OAgs and O-AGC is usually closely related to OAg, an elucidation of OAg structures needs to be conducted in the future to provide an insight into the evolution of the O-AGCs of novel serotypes.

The presence and length of OAgs play a key role in bacterial pathogenesis, and they protect the bacteria by evading the host innate immune response. ExPEC strains such as UPEC and NMEC are always triggered to be resistant to host systemic immunity by expressing specific surface polysaccharides, mainly including a capsule and/or OAg [21, 22, 34]. While the host-diarrheagenic E. coli interactions are primarily mediated by bacterial invasive virulence factors, the role of surface polysaccharides in the pathogenesis and regulation of intestinal inflammation remains unclear. Recently, it has been reported that the OAg of adherent-invasive E. coli (AIEC) can reduce its ability to adhere to and invade intestinal epithelial cells in vitro and regulate host inflammation via complement C3 [35]. EPEC can be further divided into "typical" and "atypical" subtypes based on the presence or absence of $E$. coli adherence factor plasmid [36] with each subtype containing frequently isolated serotypes or being non-typeable [14]. To the best of our knowledge, whether OAg affects the adhesion to and invasion into the intestinal epithelial cells of EPEC is rarely studied. A much earlier study reported that an EPEC strain, B171 (serotype O111), exhibits localized adherence to HeLa cells and this process is mediated by the OAg encoded by plasmid pYR111 [37]. In the present study, we investigated the role of OAg in the adhesion of EPEC to HeLa cells. The increased adhesion abilities of EPEC001 $\triangle \mathrm{OAg}$ and EPEC008 OAg derivatives are very similar to those observed in Shigella sonnei [38], Salmonella enterica [39], and Burkholderia cenocepacia [40]. All these findings suggest that OAg may mask one or more bacterial surface adhesins and OAg expression modulates bacterial 
pathogenesis by balancing their adherent and invasive capabilities and conferring optimal protection against host defense mechanisms. However, EPEC001 $w z y$ generates an opposite result, that is, this OAg isogenic strain attenuated the adherent ability to HeLa cells, similar to that observed in AIEC [35] and Plesiomonas shigelloides [41]. Another report also revealed that the deletion of the $w z y$ gene significantly decreases the adherent and invasive abilities of avian pathogenic E. coli [42]. Thus, contrasting conclusions exist on the pathogenesis of OAgs in different species and strains. We propose that on one hand, this is attributed to the different chemical structures of OAgs. On the other hand, OAg may indirectly contribute to pathogenesis, that is, its expression may be regulated by various upstream signals and other virulence factors can also be adjusted by OAg. Therefore, the OAg-associated regulatory pathway of pathogens needs to be further characterized individually.

In general, we characterized and identified two EPEC serotypes in silico and experimentally, thus further expanding the current $E$. coli serotyping scheme. We also evaluated the in vitro adherent capabilities of the OAgs of two strains, and our findings highlight the fundamental and pathogenic role of OAg in EPEC.

\section{Acknowledgments}

This work was supported by the Shandong Medical and Health Science and Technology Development Programs [Grant No. 2017WS455], the Shandong Preventive Medicine Association Zhifei Disease Prevention and Control Technology Research Fund Project [Grant No. LYH2017-03], and a grant from the Tianjin Municipal Natural Science Foundation [Grant No. 17JCYBJC24300].

\section{Conflict of Interest}

The authors have no financial conflicts of interest to declare.

\section{References}

1. Kaper JB, Nataro JP, Mobley HL. 2004. Pathogenic Escherichia coli. Nat. Rev. Microbiol. 2: 123-140.

2. Fratamico PM, DebRoy C, Liu Y, Needleman DS, Baranzoni GM, Feng P. 2016. Advances in molecular serotyping and subtyping of Escherichia coli. Front. Microbiol. 7: 644.

3. Smith JL, Fratamico PM, Gunther N. 2007. Extraintestinal pathogenic Escherichia coli (ExPEC). Foodborne Pathog. Dis. 4: $134-163$.

4. Hu J, Torres AG. 2015. Enteropathogenic Escherichia coli: foe or innocent bystander? Clin. Microbiol. Infect. 21: 729-34.

5. Merino S, Gonzalez V, Tomás JM. 2016. The first sugar of the repeat units is essential for the Wzy polymerase activity and elongation of the O-antigen lipopolysaccharide. Future Microbiol. 11: 903-918.

6. Liu B, Furevi A, Perepelov AV, Guo X, Cao H, Wang Q, et al. 2020. Structure and genetics of Escherichia coli O antigens. FEMS Microbiol. Rev. 44: 655-683.

7. Ooka T, Seto K, Ogura Y, et al. 2019. O-antigen biosynthesis gene clusters of Escherichia albertii: their diversity and similarity to Escherichia coli gene clusters and the development of an O-genotyping method. Microb. Genom. 5: e000314.

8. Amor PA, Whitfield C. 1997. Molecular and functional analysis of genes required for expression of group IB K antigens in Escherichia coli: characterization of the his-region containing gene clusters for multiple cell-surface polysaccharides. Mol. Microbiol. 26: $145-161$.

9. Sugiyama T, Kido N, Kato Y, Koide N, Yoshida T, Yokochi T. 1998. Generation of Escherichia coli O9a serotype, a subtype of E. coli O9, by transfer of the $w b^{*}$ gene cluster of Klebsiella O3 into E. coli via recombination. J. Bacteriol. 180: 2775-2778.

10. Hou X, Perepelov AV, Guo X, Senchenkova SN, Shashkov AS, Liu B, et al. 2017. A gene cluster at an unusual chromosomal location responsible for the novel O-antigen synthesis in Escherichia coli O62 by the ABC transporter-dependent pathway. Glycobiology 27: 669-676.

11. Eichler J, Imperiali B. 2018. Stereochemical divergence of polyprenolphosphate glycosyltransferases. Trends Biochem. Sci. 43: 10-17.

12. Islam ST, Lam JS. 2014. Synthesis of bacterial polysaccharides via the Wzx/Wzy-dependent pathway. Can. J. Microbiol. 60: 697-716.

13. Greenfield LK, Whitfield C. 2012. Synthesis of lipopolysaccharide O-antigens by ABC transporter-dependent pathways. Carbohydr. Res. 356: 12-24.

14. Croxen MA, Law RJ, Scholz R, Keeney KM, Wlodarska M, Finlay BB. 2013. Recent advances in understanding enteric pathogenic Escherichia coli. Clin. Microbiol. Rev. 26: 822-880.

15. McDaniel TK, Jarvis KG, Donnenberg MS, Kaper JB. 1995. A genetic locus of enterocyte effacement conserved among diverse enterobacterial pathogens. Proc. Natl. Acad. Sci. USA 92: 1664-1668.

16. Cleary J, Lai LC, Shaw RK, Straatman-Iwanowska A, Donnenberg MS, Frankel G, et al. 2004. Enteropathogenic Escherichia coli (EPEC) adhesion to intestinal epithelial cells: role of bundle-forming pili (BFP), EspA filaments and intimin. Microbiology (Reading) 150: $527-538$.

17. Martins FH, Kumar A, Abe CM, Carvalho E, Nishiyama-Jr M, Xing C, et al. 2020. EspFu-mediated actin assembly enhances enteropathogenic Escherichia coli adherence and activates host cell inflammatory signaling pathways. mBio 11: e00617-20.

18. March C, Cano V, Moranta D, Llobet E, Pérez-Gutiérrez C, Tomás JM, et al. 2013. Role of bacterial surface structures on the interaction of Klebsiella pneumoniae with phagocytes. PLoS One 8: e56847.

19. Plainvert C, Bidet P, Peigne C, Barbe V, Médigue C, Denamur E, et al. 2007. A new O-antigen gene cluster has a key role in the virulence of the Escherichia coli meningitis clone O45:K1:H7. J. Bacteriol. 189: 8528-8536.

20. Sarkar S, Ulett GC, Totsika M, Phan MD, Schembri MA. 2014. Role of capsule and O antigen in the virulence of uropathogenic Escherichia coli. PLoS One 9: e94786.

21. Bao Y, Zhang H, Huang X, Ma J, Logue CM, Nolan LK, et al. 2018. O-specific polysaccharide confers lysozyme resistance to extraintestinal pathogenic Escherichia coli. Virulence 9: 666-680

22. Vila J, Sáez-López E, Johnson JR, et al. 2016. Escherichia coli: an old friend with new tidings. FEMS Microbiol. Rev. 40: 437-463.

23. Rutherford K, Parkhill J, Crook J, Horsnell T, Rice P, Rajandream MA, et al. 2000. Artemis: sequence visualization and annotation. Bioinformatics 16: 944-945.

24. Henikoff S, Henikoff JG, Alford WJ, Pietrokovski S. 1995. Automated construction and graphical presentation of protein blocks from unaligned sequences. Gene 163: GC17-26.

25. Altschul SF, Madden TL, Schäffer AA, Zhang J, Zhang Z, Miller W, et al. 1997. Gapped BLAST and PSI-BLAST: a new generation of protein database search programs. Nucleic Acids Res. 25: 3389-3402.

26. Datsenko KA, Wanner BL. 2000. One-step inactivation of chromosomal genes in Escherichia coli K-12 using PCR products. Proc. Natl. Acad. Sci. USA 97: 6640-6645. 
27. Davis MR Jr, Goldberg JB. 2012. Purification and visualization of lipopolysaccharide from Gram-negative bacteria by hot aqueousphenol extraction. J. Vis. Exp. 63: 3916.

28. Iguchi A, Iyoda S, Seto K, Morita-Ishihara T, Scheutz F, Ohnishi M, et al. 2015. Escherichia coli O-Genotyping PCR: a comprehensive and practical platform for molecular O serogrouping. J. Clin. Microbiol. 53: 2427-2432.

29. Maguire M, Kase JA, Roberson D, Muruvanda T, Brown EW, Allard M, et al. 2021. Precision long-read metagenomics sequencing for food safety by detection and assembly of Shiga toxin-producing Escherichia coli in irrigation water. PLoS One 16: e0245172.

30. Muniesa M, Hammerl JA, Hertwig S, Appel B, Brüssow H. 2012. Shiga toxin-producing Escherichia coli O104:H4: a new challenge for microbiology. Appl. Environ. Microbiol. 78: 4065-4073.

31. Chen M, Shpirt AM, Guo X, Shashkov AS, Zhuang Y, Wang L, et al. 2015. Identification serologically, chemically and genetically of two Escherichia coli strains as candidates for new O serogroups. Microbiology 161: 1790-1796.

32. Iguchi A, von Mentzer A, Kikuchi T, Thomson NR. 2017. An untypeable enterotoxigenic Escherichia coli represents one of the dominant types causing human disease. Microb. Genom. 3: e000121.

33. Lang C, Hiller M, Konrad R, Fruth A, Flieger A. 2019. Whole-genome-based public health surveillance of less common shiga toxinproducing Escherichia coli serovars and untypeable strains identifies four novel O genotypes. J. Clin. Microbiol. 57: e00768-19.

34. Lüthje P, Brauner A. 2014. Virulence factors of uropathogenic E. coli and their interaction with the host. Adv. Microb. Physiol. 65: 337372 .

35. Ohno M, Hasegawa M, Hayashi A, Caballero-Flores G, Alteri CJ, Lawley TD, et al. 2020. Lipopolysaccharide O structure of adherent and invasive Escherichia coli regulates intestinal inflammation via complement C3. PLoS Pathog. 16: e1008928.

36. Trabulsi LR, Keller R, Tardelli Gomes TA. 2002. Typical and atypical enteropathogenic Escherichia coli. Emerg. Infect. Dis. 8: 508-513.

37. Riley LW, Junio LN, Libaek LB, Schoolnik GK. 1987. Plasmid-encoded expression of lipopolysaccharide O-antigenic polysaccharide in enteropathogenic Escherichia coli. Infect. Immun. 55: 2052-2056.

38. Caboni M, Pédron T, Rossi O, Goulding D, Pickard D, Citiulo F, et al. 2015. An O antigen capsule modulates bacterial pathogenesis in Shigella sonnei. PLoS Pathog. 11: e1004749.

39. Hölzer SU, Schlumberger MC, Jäckel D, Hensel M. 2009. Effect of the O-antigen length of lipopolysaccharide on the functions of Type III secretion systems in Salmonella enterica. Infect. Immun. 77: 5458-5470.

40. Saldías MS, Ortega X, Valvano MA. 2009. Burkholderia cenocepacia O antigen lipopolysaccharide prevents phagocytosis by macrophages and adhesion to epithelial cells. J. Med. Microbiol. 58: 1542-1548.

41. Aquilini E, Merino S, Tomás JM. 2013. The Plesiomonas shigelloides wb(O1) gene cluster and the role of O1-antigen LPS in pathogenicity. Microb. Pathog. 63: 1-7.

42. Zuo J, Tu C, Wang Y, Qi K, Hu J, Wang Z, et al. 2019. The role of the wzy gene in lipopolysaccharide biosynthesis and pathogenesis of avian pathogenic Escherichia coli. Microb. Pathog. 127: 296-303. 